\title{
BMJ Open Women's knowledge and attitudes surrounding abortion in Zambia: a cross-sectional survey across three provinces
}

\author{
Jenny A Cresswell, ${ }^{1}$ Rosalyn Schroeder, ${ }^{1,2}$ Mardieh Dennis, ${ }^{3}$ Onikepe Owolabi, ${ }^{1}$ \\ Bellington Vwalika, ${ }^{4}$ Maurice Musheke, ${ }^{3}$ Oona Campbell, ${ }^{1}$ Veronique Filippi ${ }^{1}$
}

To cite: Cresswell JA, Schroeder R, Dennis M, et al. Women's knowledge and attitudes surrounding abortion in Zambia: a crosssectional survey across three provinces. BMJ Open 2016;6: e010076. doi:10.1136/ bmjopen-2015-010076

- Prepublication history and additional material is available. To view please visit the journal (http://dx.doi.org/ 10.1136/bmjopen-2015010076)

Received 23 September 2015 Revised 15 January 2016 Accepted 1 February 2016

\section{CrossMark}

${ }^{1}$ MARCH Centre for Maternal, Adolescent, Reproductive and Child Health, LSHTM, London, UK

${ }^{2}$ Bixby Center for Global Reproductive Health, University of California, San Francisco, California, USA

${ }^{3}$ Population Council, Lusaka, Zambia

${ }^{4}$ Department of Obstetrics and Gynaecology, University of Zambia School of Medicine, Lusaka, Zambia

Correspondence to Dr Jenny A Cresswell; jenny.cresswell@Ishtm.ac.uk

\section{ABSTRACT}

Objectives: In Zambia, despite a relatively liberal legal framework, there remains a substantial burden of unsafe abortion. Many women do not use skilled providers in a well-equipped setting, even where these are available. The aim of this study was to describe women's knowledge of the law relating to abortion and attitudes towards abortion in Zambia.

Setting: Community-based survey in Central, Copperbelt and Lusaka provinces.

Participants: 1484 women of reproductive age (15-44 years)

\section{Primary and secondary outcome measures:}

Correct knowledge of the legal grounds for abortion, attitudes towards abortion services and the previous abortions of friends, family or other confidants. Descriptive statistics and multivariable logistic regression were used to analyse how knowledge and attitudes varied according to sociodemographic characteristics.

Results: Overall, just $16 \%$ (95\% $\mathrm{Cl} 11 \%$ to $21 \%$ ) of women of reproductive age correctly identified the grounds for which abortion is legal. Only $40 \%(95 \% \mathrm{Cl}$ $32 \%$ to $45 \%$ of women of reproductive age knew that abortion was legally permitted in the extreme situation where the pregnancy threatens the life of the mother. Even in urban areas of Lusaka province, only $55 \%$ $(95 \% \mathrm{Cl} 41 \%$ to $67 \%)$ of women knew that an abortion could legally take place to save the mother's life. Attitudes remain conservative. Women with correct knowledge of abortion law in Zambia tended to have more liberal attitudes towards abortion and access to safe abortion services. Neither correct knowledge of the law nor attitudes towards abortion were associated with knowing someone who previously had an induced abortion.

Conclusions: Poor knowledge and conservative attitudes are important obstacles to accessing safe abortion services. Changing knowledge and attitudes can be challenging for policymakers and public health practitioners alike. Zambia could draw on its previous experience in dealing with its large HIV epidemic to learn cross-cutting lessons in effective mass communication on what is a difficult and sensitive issue.

\section{Strengths and limitations of this study}

- The study was a population-representative, community-based survey with a good sample size, carried out across three provinces in Zambia.

- We were able to collect data on a large number of variables relating to reproductive health, including information on induced abortions among the participant's confidants, which are not frequently collected.

- However, our study also had some limitations: measuring attitudes and beliefs quantitatively is complex, and may be seen to be over-simplifying complex phenomena.

- Social desirability bias may have conceivably affected the responses to the questionnaire.

\section{INTRODUCTION}

Abortion is a sensitive and frequently stigmatised topic, both politically and socially. The issue is frequently surrounded by secrecy, shame and misconceptions, which can lead to negative health and social consequences. ${ }^{12}$ Women are more likely to attempt a clandestine, unsafe procedure if they are unaware that they could legally visit a trained health provider to obtain a safe abortion ${ }^{34}$ and may well attempt an abortion regardless of the law. ${ }^{5}$ Knowledge of the legal framework, in addition to community attitudes and stigma, can pose important barriers to accessing reproductive health services. For women themselves, even an abortion taking place in a well-equipped facility with a trained provider may not be considered as 'safe' if she is at risk from negative social consequences due to the procedure. ${ }^{6}$

In Zambia, the maternal mortality ratio in Zambia is currently estimated at 398 maternal deaths per 100000 live births, ${ }^{7}$ with around $30 \%$ of maternal deaths thought to 
be due to unsafe abortion. ${ }^{8}$ Serious morbidity due to unsafe abortion is also high (Owolabi $\mathrm{O}$, et al. The incidence of abortion-related near-miss complications in Zambia: a cross-sectional study in Central, Copperbelt and Lusaka provinces. (Forthcoming)). ${ }^{9}$ At first glance, this might seem surprising since the legal framework surrounding abortion is relatively liberal. However, health system and human resource constraints mean that, in practice, many Zambian women cannot access safe abortion services. ${ }^{10}$ The Termination of Pregnancy Act of 1972 states that an abortion may legally take place if the continuation of the pregnancy involves a risk to the pregnant woman's life, physical or mental health; a risk to the physical or mental health of any existing children; or if there is a substantial risk that the child will be born with birth abnormalities. ${ }^{11}$ The Act further specifies that the pregnant woman's actual or reasonably foreseeable environment may be taken into account. The signatures of three doctors are needed, although this requirement is waived if one doctor believes that the abortion is immediately necessary to protect the woman's health. The Penal Code was amended in 2005 to explicitly state that abortion is permitted in cases of child rape. ${ }^{8}$ In May 2009, the Ministry of Health published a set of standards and guidelines for reducing unsafe abortion; these clarified that a wide range of factors including age, economic situation, social and cultural environment, religion and marital status should be considered in determining whether continuing a pregnancy poses a risk to the woman's health, including her subjective well-being. If one or more of these conditions are met, then a trained health provider may carry out an abortion based on the woman's free consent. ${ }^{8}$ The guidelines also state that mid-level providers can provide first trimester abortions, which allow services to be decentralised and reduce the distance women need to travel in rural areas. ${ }^{8}$

Despite this relatively liberal legal framework, social attitudes towards abortion remain conservative, and knowledge of safe abortion services remains poor. ${ }^{12-14} \mathrm{~A}$ household survey carried out in four communities in the Copperbelt and Lusaka provinces in 2010 found that people had strong beliefs regarding the immorality of abortion. ${ }^{15} \mathrm{~A}$ health ranking exercise conducted in urban focus groups identified unwanted pregnancy as the most common sexual and reproductive health problem among young people. ${ }^{16}$ Within this mixedmethods study, self-induced abortion and traditional healers were considered common methods of abortion, with few participants considering going to a public health facility unless something went wrong. ${ }^{16}$ This suggests that many women may not use a trained provider even where they are available. Women may also visit a pharmacist to obtain a medical abortion, ${ }^{17}$ particularly in urban areas.

Knowledge and attitudes towards abortion services are important factors in decision-making processes for access to reproductive healthcare among Zambian women. The aim of this study was to describe women's knowledge of the law relating to abortion and attitudes towards abortion in three provinces of Zambia (Central, Copperbelt and Lusaka).

\section{METHODS}

\section{Survey design}

We conducted a community-based household survey among women of reproductive age (15-44 years) between 10 March and 6 May 2014 across Central, Copperbelt and Lusaka provinces. A multistage sampling design was used, with wards selected with probability proportional to size using the 2010 census as a sampling frame; each ward was subdivided into zones based on estimated population density and sampling took place as evenly as possible across these zones. The response rate for the survey was $86 \%$.

A structured questionnaire containing questions relating to sociodemographic characteristics, reproductive and contraceptive history and fertility preferences was administered; women were interviewed verbally with the fieldworker entering her response onto a tablet computer. Fieldworkers were females of reproductive age able to communicate fluently in English and one or more local languages; most had previous survey experience. The wording used in the Demographic and Health Surveys (DHS) was maintained wherever possible in order to facilitate comparisons. We also included a set of questions adapted from a previous study on knowledge and attitudes towards abortion conducted by Geary et $a l^{15}$ to allow us to explore whether attitudes towards abortion are changing over time. In addition, we included questions based on the anonymous third party reporting (ATPR), or 'confidant', method, ${ }^{18}{ }^{19}$ which collects data on abortions carried out by the woman's close friends, family or other confidants. The incidence findings from the ATPR will be described in a forthcoming, separate paper. Women were not asked whether they themselves had ever had an induced abortion. The questionnaire was pretested in purposively selected areas of Lusaka, varying in population density and wealth, prior to use.

All women aged 15-44 years living in selected households were invited to participate in the main survey (sociodemographic questions; questions on knowledge and attitudes, etc); however, only one woman per household was randomly selected to participate in the ATPR module. We took this decision to maintain confidentiality between household members, who otherwise could have been asked to report on each other, potentially leading to recriminations.

All women gave written informed consent to participate in the study.

\section{Statistical analysis}

Our initial analysis focused on describing the proportion of women who (1) believe abortion is legal in Zambia, 
and (2) believe abortion should be legal in Zambia, according to the reason for the abortion. Sociodemographic factors associated with better knowledge of the abortion law were investigated using multivariable logistic regression.

In addition, we used multivariable logistic regression to investigate whether women were more likely to agree or strongly agree with the statement 'abortion is immoral' according to age group, urban/rural residence, province of residence, highest education level attended, religion and whether the woman knew of at least one confidant who had an induced abortion during the 5 years preceding the survey. This analysis was repeated with women who agreed or strongly agreed with the statement "women should have access to safe abortion services' as the outcome. Data on whether the woman knew of at least one confidant who had an induced abortion during the 5 years preceding the survey came from the ATPR module, and therefore this analysis is restricted to the subgroup which was selected for this component.

All analyses were conducted using Stata V.14.0 and took the survey design (clustering and sample weights) into account.

\section{FINDINGS}

A total of 1484 women participated in this study, with 641 women providing data for the ATPR module. Our sample was predominantly urban (68\%; table 1). Most women had attended school (94\%) with over half the sample having attended secondary education or higher. Of those selected to respond to the ATPR module, 21\% knew of at least one person who had had an induced abortion over the past 5 years.

Accurate knowledge of the legal framework surrounding induced abortion in Zambia was very low (figure 1). Overall, just $16 \%$ of women of reproductive age correctly identified the grounds for which abortion is legal in Zambia. Correct knowledge was higher in urban areas than in rural areas $(19 \%$ vs $9 \% ; \mathrm{p}=0.0020)$. There was no evidence of an association between age group and correct knowledge $(\mathrm{p}=0.3974)$. The data disaggregated by province are presented in online supplementary figure S1A. Only $40 \%$ of women of reproductive age knew that the extreme situation where the pregnancy threatens the life of the mother was grounds for a legal abortion. Even in urban areas of Lusaka province, only $55 \%$ of women knew that an abortion could legally take place to save the mother's life.

Figure 2 describes women's opinions on whether they believe abortion should be legal in Zambia for various grounds, stratified by whether or not they think abortion is currently legal for that reason. The proportion of women who knew that abortion was legal for a given grounds, but believed that it should not be, remained relatively constant at just under $10 \%$, regardless of the reason for the abortion. A similar proportion of women
Table 1 Characteristics of the sample $(\mathrm{N}=1484)$

\begin{tabular}{lrr}
\hline & N & Per cent \\
\hline $\begin{array}{l}\text { Knows } \geq 1 \text { person who has induced an } \\
\text { abortion in the past } 5 \text { years }\end{array}$ & & \\
No & 505 & 79 \\
Yes & 136 & 21 \\
$\quad$ Did not provide data for the ATPR & 843 & - \\
$\quad$ module & & \\
Age group (years) & 726 & 49 \\
15-24 & 486 & 33 \\
25-34 & 273 & 18 \\
35-44 & & \\
Area of residence & 1014 & 68 \\
$\quad$ Urban & 470 & 32 \\
$\quad$ Rural & 345 & 23 \\
Province of residence & 533 & 36 \\
$\quad$ Central & 606 & 41 \\
$\quad$ Copperbelt & & \\
$\quad$ Lusaka & 58 & 4 \\
Highest level of education attended & 485 & 33 \\
$\quad$ None & 842 & 57 \\
$\quad$ Primary & 99 & 7 \\
$\quad$ Secondary & & \\
$\quad$ Higher education & 249 & 17 \\
Religion & 1224 & 82 \\
$\quad$ Catholic & 10 & 1 \\
$\quad$ Other Christian & & \\
Other & & \\
ATPR, anonymous third party reporting. &
\end{tabular}

(around 10\%) did not know that abortion was legal for a given grounds, yet believed that it should be permitted. However, an increasing proportion of women were more likely to both think abortion was legal for a given grounds and believe that it should be legal for that reason as the severity of grounds for the procedure increased.

Overall, $15 \%$ of women said that they thought abortion should be legal regardless of reason, while $39 \%$ of women thought that a pregnancy that threatened the woman's life should be grounds for a legal abortion.

Women's attitudes towards abortion were generally very conservative (figure 3). More than $90 \%$ of women either agreed or strongly agreed with the statement 'abortion is immoral'. Conversely, the majority of women either disagreed or strongly disagreed with the statements 'women should have access to safe abortion services' ( $71 \%$ ); and 'unmarried women should have access to safe abortion services' (79\%). The prompt 'a woman has the right to decide whether to continue with a pregnancy' elicited more mixed responses.

The accuracy of women's knowledge regarding the abortion law was strongly associated with their level of education (table 2). After adjusting for other sociodemographic characteristics, the odds of a woman correctly knowing the legal grounds for abortion in Zambia were over four times higher among women who had attended higher (tertiary) education compared to those with 


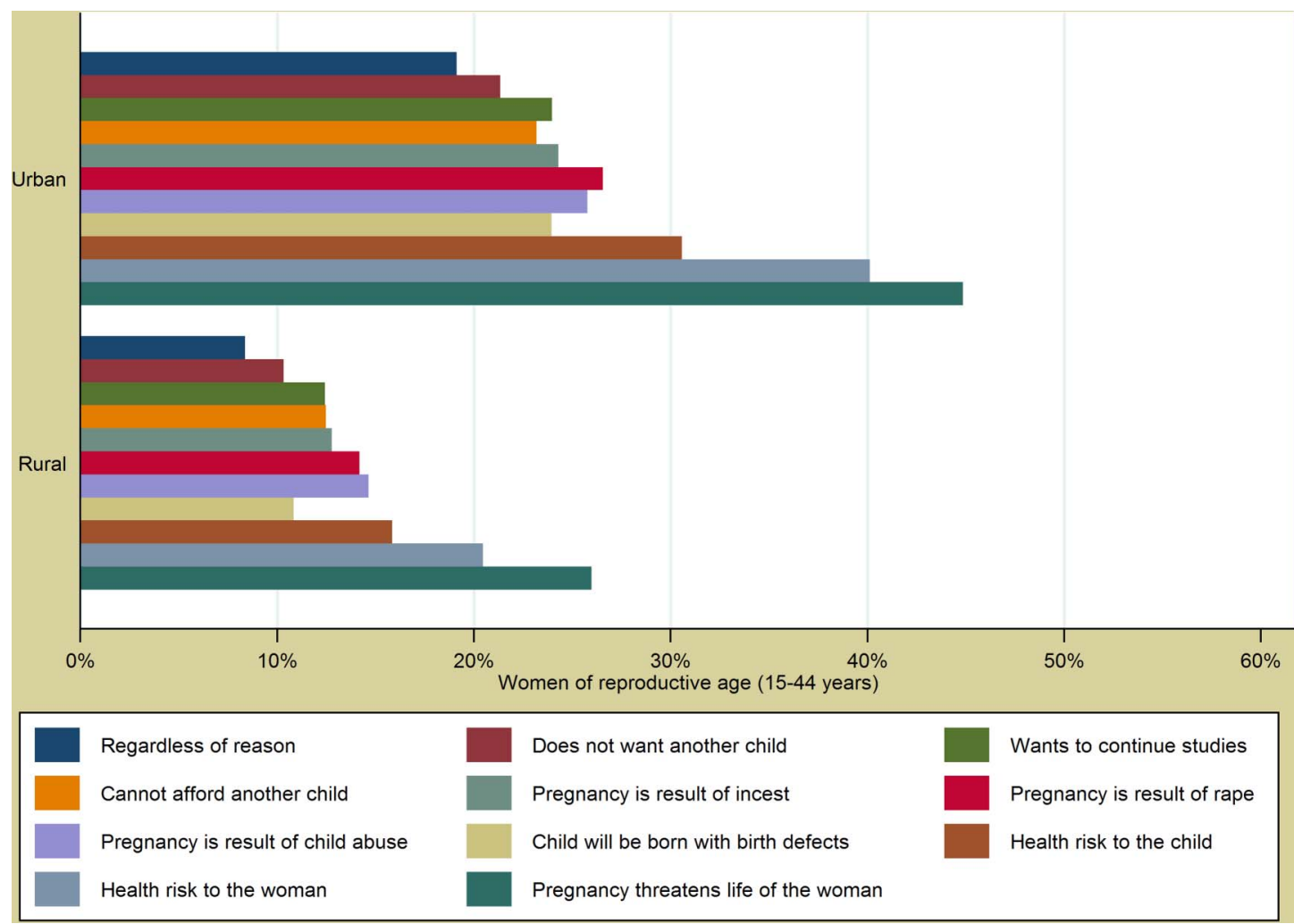

Figure 1 Abortion knowledge: legal grounds for which women of reproductive age think abortion is permitted in Central, Copperbelt and Lusaka provinces, stratified urban/rural $(\mathrm{N}=1484)$.

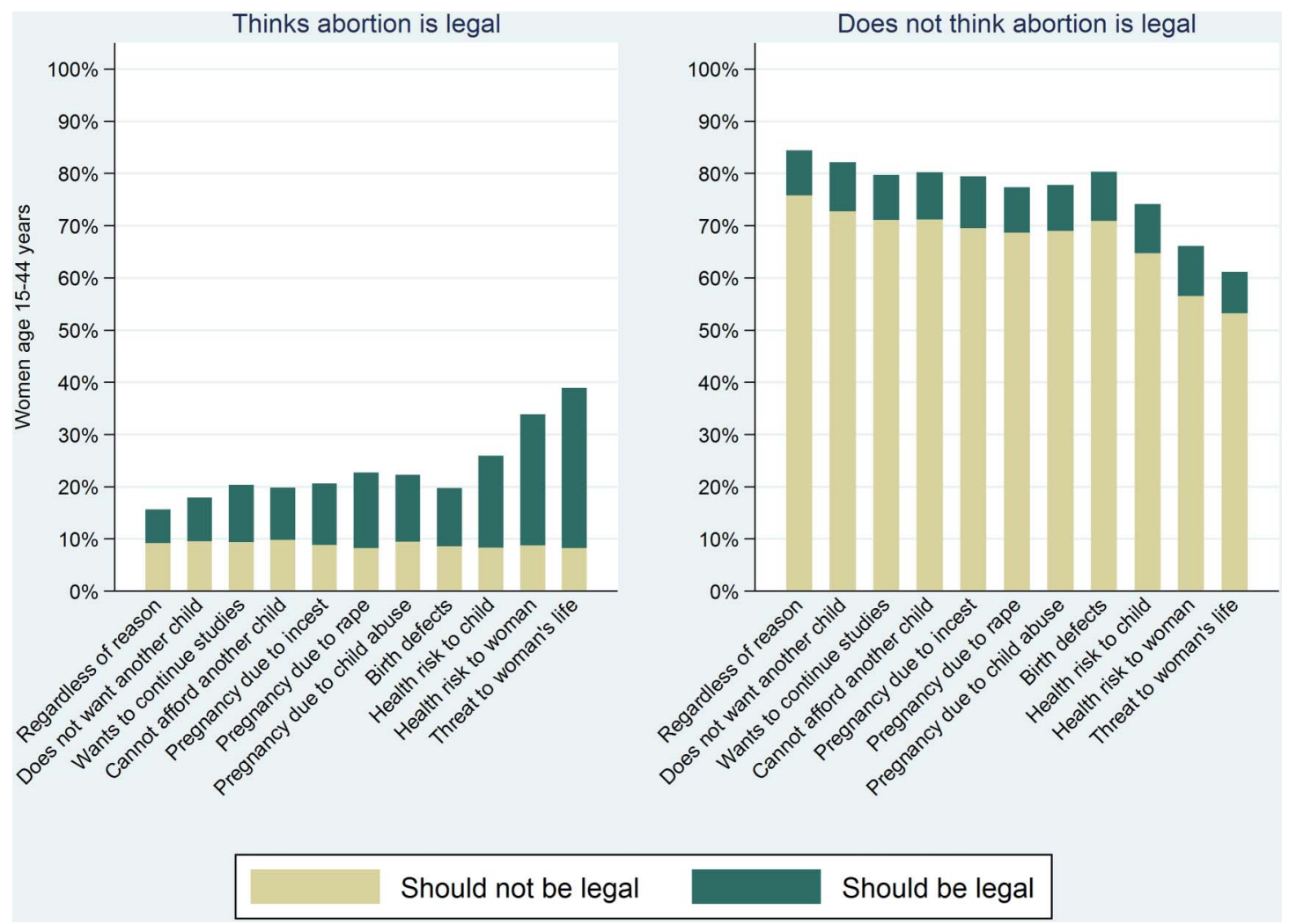

Figure 2 Women's beliefs regarding whether abortion should be legal in Zambia, stratified by grounds for the procedure, and whether she thinks abortion is currently legal or not $(\mathrm{N}=1484)$. 


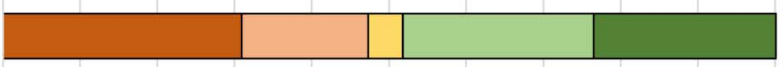

"Women should have access to safe abortion services"

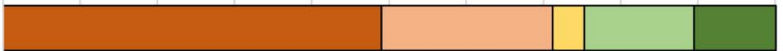

"Unmarried women should have access to safe abortion services"

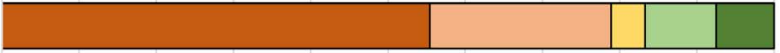

$\square$ Strongly disagree $\square$ Disagree $\square$ Neutral $\square$ Agree $\square$ Strongly agree

Figure 3 Women's attitudes towards abortion in Central, Copperbelt and Lusaka provinces (N=1484).

primary education only. Women's knowledge of the law was not associated with whether or not they knew of someone who had had an induced abortion $(\mathrm{p}=0.7111)$.

Women with correct knowledge of abortion law in Zambia tended to have more liberal attitudes towards abortion (tables 3 and 4). There was some evidence that older women aged 35-44 years were more likely to believe abortion to be immoral than younger women (table 3). We found evidence of a crude relationship between level of education and whether a woman believed "women should have access to safe abortion services', with more educated women being more likely to agree with the statement. However, after adjusting for confounders, this relationship was no longer statistically significant (table 4 ).

\section{DISCUSSION}

Our findings show very low knowledge of the legal status of abortion among women of reproductive age in

Table 2 Association between whether a woman has correct knowledge of the legal status of abortion and whether the woman knows at least one person who has terminated a pregnancy in the past 5 years adjusted for sociodemographic characteristics $(\mathrm{N}=641)$

\begin{tabular}{|c|c|c|c|c|}
\hline & \multicolumn{2}{|l|}{ Unadjusted } & \multicolumn{2}{|l|}{ Adjusted* } \\
\hline & OR (95\% Cl) & p Value & OR (95\% Cl) & p Value \\
\hline \multicolumn{5}{|c|}{ Knows $\geq 1$ person who has induced an abortion in the past 5 years } \\
\hline No & 1.00 & \multirow[t]{2}{*}{0.5055} & 1.00 & \multirow[t]{2}{*}{0.7111} \\
\hline Yes & $1.27(0.62$ to 2.57$)$ & & $1.17(0.50$ to 2.72$)$ & \\
\hline \multicolumn{5}{|l|}{ Age group (years) } \\
\hline $15-24$ & 1.00 & \multirow[t]{3}{*}{0.7018} & 1.00 & \multirow[t]{3}{*}{0.1392} \\
\hline 25-34 & $0.84(0.55$ to 1.27$)$ & & $0.53(0.28$ to 0.99$)$ & \\
\hline $35-44$ & $0.80(0.33$ to 1.96$)$ & & $0.77(0.25$ to 2.30$)$ & \\
\hline \multicolumn{5}{|l|}{ Area of residence } \\
\hline Urban & 1.00 & \multirow[t]{2}{*}{0.4216} & 1.00 & \multirow[t]{2}{*}{0.1598} \\
\hline Rural & $0.71(0.31$ to 1.64$)$ & & $0.54(0.22$ to 1.29$)$ & \\
\hline \multicolumn{5}{|l|}{ Province of residence } \\
\hline Central & 1.00 & \multirow[t]{3}{*}{0.2045} & 1.00 & \multirow[t]{3}{*}{0.4421} \\
\hline Copperbelt & $0.71(0.30$ to 1.68$)$ & & $0.63(0.21$ to 1.84$)$ & \\
\hline Lusaka & $1.37(0.49$ to 3.81$)$ & & 1.03 (0.33 to 3.25$)$ & \\
\hline \multicolumn{5}{|c|}{ Highest level of education attended } \\
\hline None & $3.11(1.70$ to 5.69$)$ & \multirow[t]{4}{*}{$<0.0001$} & $0.85(0.07$ to 10.28$)$ & \multirow[t]{4}{*}{0.0063} \\
\hline Primary & 1.00 & & 1.00 & \\
\hline Secondary & $2.06(1.17$ to 3.64$)$ & & $1.29(0.38$ to 4.43$)$ & \\
\hline Higher education & 4.90 (2.12 to 11.29$)$ & & $4.68(1.52$ to 14.37$)$ & \\
\hline \multicolumn{5}{|l|}{ Religion } \\
\hline Catholic & 1.00 & \multirow[t]{3}{*}{0.8361} & 1.00 & \multirow[t]{3}{*}{0.1287} \\
\hline Other Christian & 1.19 (0.64 to 2.22) & & $2.16(0.87$ to 5.34$)$ & \\
\hline Other & $0.95(0.10$ to 9.30$)$ & & $0.17(0.01$ to 3.58$)$ & \\
\hline
\end{tabular}


Table 3 Association between whether a woman agrees or strongly agrees with the statement 'abortion is immoral' and whether the woman knows at least one person who has terminated a pregnancy in the past 5 years adjusted for sociodemographic characteristics $(\mathrm{N}=641)$

\begin{tabular}{|c|c|c|c|c|}
\hline & \multicolumn{2}{|l|}{ Unadjusted } & \multicolumn{2}{|l|}{ Adjusted* } \\
\hline & OR (95\% Cl) & p Value & OR (95\% Cl) & p Value \\
\hline \multicolumn{5}{|c|}{ Knows $\geq 1$ person who has induced an abortion in the past 5 years } \\
\hline No & 1.00 & \multirow[t]{2}{*}{0.2091} & 1.00 & \multirow[t]{2}{*}{0.3690} \\
\hline Yes & $0.67(0.36$ to 1.26$)$ & & $0.74(0.38$ to 1.44$)$ & \\
\hline \multicolumn{5}{|c|}{ Has correct knowledge of the abortion law in Zambia } \\
\hline No & 1.00 & \multirow[t]{2}{*}{$<0.0001$} & 1.00 & \multirow[t]{2}{*}{0.0335} \\
\hline Yes & $0.28(0.17$ to 0.44$)$ & & $0.23(0.06$ to 0.89$)$ & \\
\hline \multicolumn{5}{|l|}{ Age group (years) } \\
\hline $15-24$ & 1.00 & \multirow[t]{3}{*}{0.7197} & 1.00 & \multirow[t]{3}{*}{0.0481} \\
\hline $25-34$ & $0.84(0.55$ to 1.29$)$ & & $0.60(0.18$ to 2.02$)$ & \\
\hline $35-44$ & $1.01(0.45$ to 2.28$)$ & & 2.92 (0.98 to 8.72$)$ & \\
\hline \multicolumn{5}{|l|}{ Area of residence } \\
\hline Urban & 1.00 & \multirow[t]{2}{*}{0.3651} & 1.00 & \multirow[t]{2}{*}{0.5019} \\
\hline Rural & $1.33(0.71$ to 2.49$)$ & & $1.38(0.53$ to 3.59$)$ & \\
\hline \multicolumn{5}{|l|}{ Province of residence } \\
\hline Central & 1.00 & \multirow[t]{3}{*}{0.0095} & 1.00 & \multirow[t]{3}{*}{0.2338} \\
\hline Copperbelt & $1.86(0.92$ to 3.80$)$ & & 1.51 (0.53 to 4.29$)$ & \\
\hline Lusaka & $0.63(0.33$ to 1.21$)$ & & $0.88(0.32$ to 2.43$)$ & \\
\hline \multicolumn{5}{|c|}{ Highest level of education attended } \\
\hline None & $1.64(0.34$ to 7.79$)$ & \multirow[t]{4}{*}{0.3841} & $4.14(0.42$ to 41.09$)$ & \multirow[t]{4}{*}{0.5532} \\
\hline Primary & 1.00 & & 1.00 & \\
\hline Secondary & 1.39 (0.84 to 2.31$)$ & & $1.33(0.42$ to 4.29$)$ & \\
\hline Higher education & $0.69(0.29$ to 1.64$)$ & & $0.83(0.25$ to 2.78$)$ & \\
\hline \multicolumn{5}{|l|}{ Religion } \\
\hline Catholic & 1.00 & \multirow[t]{3}{*}{0.1608} & 1.00 & \multirow[t]{3}{*}{0.4465} \\
\hline Other Christian & $0.56(0.24$ to 1.27$)$ & & 0.56 (0.12 to 2.59$)$ & \\
\hline Other & $\infty$ & & $\infty$ & \\
\hline
\end{tabular}

${ }^{*}$ Adjusted for all other variables in the model.

†All women within this category agreed with the statement 'abortion is immoral'; thus, the OR is not calculable.

Zambia and high levels of conservative attitudes. Across the three provinces, less than one-fifth of women correctly knew the legal status of abortion in Zambia, with only two-fifths knowing that abortion was allowed in the most extreme situation to save the life of a pregnant woman. This is lower than the prevalence of correct knowledge that is reported in studies in South Africa $(32 \%),{ }^{20}$ Mexico $(45 \%)^{21}$ and Ethiopia $(48 \%) .{ }^{22}$

Correct knowledge of abortion law among women was very low even in urban Lusaka (23\%). This is despite living in close proximity to University Teaching Hospital (UTH), a very large referral facility which provides abortions on request as long as women comply with the broad legal framework. ${ }^{23}$ Our findings may explain why, even at UTH, only around $8 \%$ of all abortion-related admissions seen at the facility are safe, legal procedures. ${ }^{23}$ Women who are considering terminating an unwanted pregnancy but who are unaware of the legal framework are much less likely to approach a trained health provider ${ }^{24}$ and may instead seek assistance through other means. Self-induced abortions and abortions performed by untrained providers are less safe and also illegal in Zambia.

Some previous studies in Zambia have suggested that the burden of unsafe abortion is greatest among adolescents and younger women. ${ }^{9}{ }^{16}$ In our study, we found no evidence of any association between age and knowledge, and limited evidence between age and attitudes towards abortion, similar to a previous study in Zambia. ${ }^{15}$ Proving information on reproductive health in school is sensitive in Zambia. ${ }^{25}{ }^{26}$ Nevertheless, a school-based programme such as the Comprehensive Sexuality Education curriculum for senior secondary school students may be a good channel for an information-delivery intervention, ${ }^{27} 28$ given that schools are one of the few institutions in regular contact with a sizeable proportion of adolescents. According to the most recent DHS, $55 \%$ of women aged $15-19$ years had at least some secondary education. ${ }^{7}$ A community-based survey in Western province found that girls attending secondary school were not well informed about reproductive and sexual health issues, as schools had no formal sex education programme and few girls discussed such matters with their parents. ${ }^{9}$ Similar themes have been observed among adolescent girls admitted to UTH for incomplete abortions. ${ }^{29}$ Initiatives that combine educational and contraceptive interventions have been shown to reduce unintended pregnancies among adolescents. $^{30}$ In addition, providing medical staff with 
Table 4 Association between whether a woman agrees or strongly agrees with the statement 'women should have access to safe abortion services' and whether the woman knows at least one person who has terminated a pregnancy in the past 5 years adjusted for sociodemographic characteristics $(\mathrm{N}=641)$

\begin{tabular}{|c|c|c|c|c|}
\hline & \multicolumn{2}{|l|}{ Unadjusted } & \multicolumn{2}{|l|}{ Adjusted* } \\
\hline & OR (95\% Cl) & p Value & OR (95\% Cl) & p Value \\
\hline \multicolumn{5}{|c|}{ Knows $\geq 1$ person who has induced an abortion in the past 5 years } \\
\hline Yes & 1.40 (0.86 to 2.29$)$ & 0.1672 & $1.26(0.68$ to 2.35$)$ & 0.4588 \\
\hline \multicolumn{5}{|c|}{ Has correct knowledge of the abortion law in Zambia } \\
\hline No & 1.00 & $<0.0001$ & 1.00 & 0.0384 \\
\hline $15-24$ & 1.00 & \multirow{3}{*}{0.4016} & 1.00 & \multirow{3}{*}{0.3256} \\
\hline $25-34$ & $0.91(0.67$ to 1.23$)$ & & $0.84(0.50$ to 1.41$)$ & \\
\hline $35-44$ & $0.70(0.40$ to 1.20$)$ & & $1.37(0.64$ to 2.92$)$ & \\
\hline \multicolumn{5}{|l|}{ Area of residence } \\
\hline Urban & 1.00 & 0.5932 & 1.00 & 0.0868 \\
\hline Lusaka & $0.77(0.42$ to 1.41$)$ & 0.5111 & $1.02(0.51$ to 2.04$)$ & 0.9109 \\
\hline \multicolumn{5}{|c|}{ Highest level of education attended } \\
\hline None & $2.06(0.95$ to 4.47$)$ & \multirow[t]{4}{*}{0.0021} & 2.89 (0.77 to 10.82$)$ & \multirow[t]{4}{*}{0.4711} \\
\hline Primary & 1.00 & & 1.00 & \\
\hline Secondary & 2.24 (1.42 to 3.54$)$ & & $1.30(0.60$ to 2.80$)$ & \\
\hline Higher education & 3.37 (1.46 to 7.77$)$ & & $1.33(0.37$ to 4.70$)$ & \\
\hline \multicolumn{5}{|l|}{ Religion } \\
\hline Catholic & 1.00 & \multirow[t]{3}{*}{0.1952} & 1.00 & \multirow[t]{3}{*}{0.0765} \\
\hline Other Christian & $0.73(0.45$ to 1.18$)$ & & 0.57 (0.30 to 1.06$)$ & \\
\hline Other & $\dagger$ & & $\dagger$ & \\
\hline
\end{tabular}

continuing education related to adolescent sexual and reproductive health and legality of abortion in Zambia may well improve service provision for this age group. ${ }^{31}$

Changing community knowledge and attitudes can be challenging, particularly when the topic is stigmatised. Additional interventions are needed to increase access to reproductive health services, including safe abortion services, among older age groups who are no longer at school. Mass media interventions are one option; $51 \%$ of women of reproductive age in Zambia listen to radio at least once a week, and $40 \%$ watch television at least once a week. ${ }^{7}$ There is some evidence that radio campaigns have been successful in increasing condom use in Zambia. $^{32}$ However, interventions focused on increasing knowledge of safe abortion services in other settings, such as India, have found interpersonal communication with family and existing community health workers to be a promising approach. ${ }^{43}$ Ultimately, it is not just women but the entire community which needs to be targeted. Moving forward, it is essential to ensure that safe services exist and to widely communicate where and when such services are available, should women wish to access them.

Since 2010, when Geary et al ${ }^{15}$ conducted their survey, attitudes towards abortion have generally remained conservative. Their study found that $88 \%$ of people strongly agreed that abortion is immoral, compared to $75 \%$ of women in our study. However, they found that $41 \%$ of people strongly agreed that women should have access to safe abortion services. ${ }^{15}$ In our study, this was just $11 \%$, with a further $14 \%$ being in agreement. It should be noted that there were differences in design between the two studies: our study took place across a much wider geographical area, whereas the Geary et al study combined both men and women. These findings are of particular concern to those arguing for the provision of safe abortion services, given that a draft revision of Zambia's constitution defined the right to life as beginning at conception. ${ }^{34}$ At the time of writing, although the Zambian President signed into law the Constitution of Zambia Amendment Bill of 2015 on 5 January 2016, the enacted constitutional amendments do not include the Article in the draft Zambian Constitution which defines life as beginning at conception. The enactment of this Article and other constitutional amendments, deemed 'contentious', has been deferred until consensus is reached among the different stakeholders.

Our study was a population-representative survey with a good sample size, carried out across three provinces. 
We were able to collect data on a large number of variables, including information on induced abortions among the participant's confidants. However, our study also had some limitations. Measuring attitudes and beliefs quantitatively is complex, and a group of researchers have recently developed a scale to measure stigmatising beliefs about abortion. ${ }^{35}$ This scale was not available at the time of our data collection, but we await future findings with interest. Past methodological research has demonstrated that question sequence can influence the proportion of women who agree that abortion should be legal for a given reason $;{ }^{36}$ this study found that more respondents agree that abortion should be legal 'for any reason' when the question is asked first, compared to when it is asked after a sequence of alternative grounds. In our study, this question was ordered first in the questionnaire; nonetheless, less than one in five women agreed that abortion should be legal for any reason. The specific phrasing of the questions themselves may also have influenced the responses in ways it is difficult to determine. Finally, it is possible that women may exaggerate their views on the immorality of abortion because they want to fit in with existing social norms. ${ }^{1} \mathrm{We}$ did not consider it feasible for our respondent's to selfadminister the questionnaire; thus, the interviewer was privy to the information disclosed and respondents may have been influenced into making more conservative statements through social desirability bias.

Zambia currently has one of the more liberal abortion legal frameworks in sub-Saharan Africa. However, in practice, poor knowledge and conservative attitudes are important obstacles to reproductive health access, which should be acknowledged alongside more frequently emphasised barriers, including a lack of trained providers, and distance to health facilities. Changing community knowledge and attitudes in stigmatised areas can be challenging for policymakers and public health practitioners alike. Zambia could draw on its previous experience in dealing with its large HIV epidemic to learn cross-cutting lessons in effective mass communication on what is a difficult and sensitive and ultimately a very personal issue.

Acknowledgements This research was funded by the UK Department for International Development. The views expressed in this manuscript represent the views of the named authors only. The authors thank our colleagues at the Population Council (Michael Mbizvo, Jennifer Price, Scott Geibel), the Guttmacher Institute (Akin Bankole, Anne Moore) and the London School of Hygiene and Tropical Medicine who have commented on the protocol development and emerging findings at various stages. The authors thank Gustavo Suarez of the Guttmacher Institute for reviewing this paper for communications purposes. The authors also thank the fieldwork team for their hard work and dedication. Most importantly, the authors thank the women who participated in this study and took the time to answer our questions.

Contributors VF conceived the study with contributions from OC. JAC designed the data collection tools with inputs from MD and 00; 00 had responsibility for the confidant method section of the questionnaire. MD managed the fieldwork. RS and JAC analysed the data. JAC drafted the manuscript. JAC, RS, MD, 00, BV, MM, OC and VF contributed to the interpretation of the data and critically reviewed drafts of the manuscript for intellectual content. All authors approved the final version of the manuscript for publication.

Funding UK Department for International Development. 00 was funded by a +3 ESRC PhD studentship [ES/J5000021/1].

Competing interests None declared.

Ethics approval Ethical approval was granted by three IRBs: the London School of Hygiene and Tropical Medicine, the University of Zambia Biomedical Research Ethics Committee (UNZABREC) and the Population Council.

Provenance and peer review Not commissioned; externally peer reviewed.

Data sharing statement No additional data are available.

Open Access This is an Open Access article distributed in accordance with the terms of the Creative Commons Attribution (CC BY 4.0) license, which permits others to distribute, remix, adapt and build upon this work, for commercial use, provided the original work is properly cited. See: http:// creativecommons.org/licenses/by/4.0/

\section{REFERENCES}

1. Kumar A, Hessini L, Mitchell EM. Conceptualising abortion stigma. Cult Health Sex 2009;11:625-39.

2. Levandowski BA, Kalilani-Phiri L, Kachale F, et al. Investigating social consequences of unwanted pregnancy and unsafe abortion in Malawi: the role of stigma. Int J Gynaecol Obstet 2012;118(Suppl 2): S167-71.

3. Banerjee SK, Andersen KL, Warvadekar J. Pathways and consequences of unsafe abortion: a comparison among women with complications after induced and spontaneous abortions in Madhya Pradesh, India. Int J Gynaecol Obstet 2012;118(Suppl 2):S113-20.

4. Banerjee SK, Andersen KL, Buchanan RM, et al. Woman-centered research on access to safe abortion services and implications for behavioral change communication interventions: a cross-sectional study of women in Bihar and Jharkhand, India. BMC Public Health 2012;12:175.

5. Sedgh $\mathrm{G}$, Singh $\mathrm{S}$, Shah $\mathrm{IH}$, et al. Induced abortion: incidence and trends worldwide from 1995 to 2008. Lancet 2012;379:625-32.

6. Izugbara CO, Egesa C, Okelo R. 'High profile health facilities can add to your trouble': women, stigma and un/safe abortion in Kenya. Soc Sci Med 2015;141:9-18.

7. Central Statistical Office. Ministry of health, and ICF international, Zambia demographic and health survey, 2013-14. Rockville, Maryland, USA: Central Statistical Office, Ministry of Health and ICF International, 2014.

8. Government of the Republic of Zambia Ministry of Health. Standards and guidelines for reducing unsafe abortion morbidity and mortality in Zambia. 2014.

9. Koster-Oyekan W. Why resort to illegal abortion in Zambia? Findings of a community-based study in Western Province. Soc Sci Med 1998;46:1303-12.

10. Ngwena CG. Protocol to the African charter on the rights of women: implications for access to abortion at the regional level. Int $J$ Gynaecol Obstet 2010;110:163-6.

11. The Termination of Pregnancy Act. Zambia, 1972

12. Kavanaugh ML, Moore AM, Akinyemi O, et al. Community attitudes towards childbearing and abortion among HIV-positive women in Nigeria and Zambia. Cult Health Sex 2013;15:160-74.

13. Kabwe CY, Abortion: should it be legalized in Zambia?, in School of Law. Lusaka, Zambia. University of Zambia, 2005

14. Moore AM, Bankole A, Awolude O, et al. Attitudes of women and men living with HIV and their healthcare providers towards pregnancy and abortion by HIV-positive women in Nigeria and Zambia. Afr J AIDS Res 2015;14:29-42.

15. Geary CW, Gebreselassie H, Awah P, et al. Attitudes toward abortion in Zambia. Int J Gynaecol Obstet 2012;118(Suppl 2): S148-51.

16. Webb D. Attitudes to 'Kaponya Mafumo': the terminators of pregnancy in urban Zambia. Health Policy Plan 2000;15:186-93.

17. Fetters T, Raisanen K, Mupeta $\mathrm{S}$, et al. Using a harm reduction lens to examine post-intervention results of medical abortion training among Zambian pharmacists. Reprod Health Matters 2015;22(Suppl 1):116-24.

18. Rossier C. Measuring abortion with the anonymous third party reporting method. In: Singh S, Remez L, Tartaglione A, eds. 
Methodologies for estimating abortion incidence and abortion-related morbidity: a review. Guttmacher Institute/IUSSP, 2010:99-106.

19. Rossier C, Guiella G, Ouédraogo A, et al. Estimating clandestine abortion with the confidants method-results from Ouagadougou, Burkina Faso. Soc Sci Med 2006;62:254-66.

20. Morroni C, Myer L, Tibazarwa K. Knowledge of the abortion legislation among South African women: a cross-sectional study. Reprod Health 2006;3:7.

21. García SG, Tatum C, Becker D, et al. Policy implications of a national public opinion survey on abortion in Mexico. Reprod Health Matters 2004;12(24 Suppl):65-74.

22. Bitew S, Ketema S, Worku M, et al. Knowledge and attitude of women of childbearing age towards the legalization of abortion, Ethiopia. J Sci Innov Res 2013;2:192-203.

23. Macha S, Muyuni M, Nkonde S, et al. Increasing access to legal termination of pregnancy and postabortion contraception at the University Teaching Hospital, Lusaka, Zambia. Int J Gynaecol Obstet 2014;126(Suppl 1):S49-51.

24. Jewkes RK, Gumede T, Westaway MS, et al. Why are women still aborting outside designated facilities in metropolitan South Africa? BJOG 2005;112:1236-42.

25. Kaluba A. Should sex education be taught in school?, in Times of Zambia. Published: 18th April 2015. http://www.times.co.zm/? $\mathrm{p}=56464$. (accessed 12 Aug 2015). 2015.

26. Zimba M. Have parents embraced sexual education?, in Times of Zambia. Published: 1st July 2015. http://www.times.co.zm/? $\mathrm{p}=62589$. (accessed 12 Aug 2015). 2015.

27. Curriculum Development Centre, Zambia Education Curriculum Framework. Ministry of education, science, vocational training and early education: Lusaka, Zambia, 2013.
28. United Nations Educational Scientific and Cultural Organization (UNESCO). Sexuality education: a ten-country review of school curricula in East and Southern Africa. UNESCO and UNFPA, 2012.

29. Dahlbäck E, Maimbolwa M, Yamba CB, et al. Pregnancy loss: spontaneous and induced abortions among young women in Lusaka, Zambia. Cult Health Sex 2010;12:247-62.

30. Oringanje $\mathrm{C}$, Meremikwu MM, Eko $\mathrm{H}$, et al. Interventions for preventing unintended pregnancies among adolescents. Cochrane Database Syst Rev 2009;(4):CD005215.

31. Warenius LU, Faxelid EA, Chishimba PN, et al. Nurse-midwives' attitudes towards adolescent sexual and reproductive health needs in Kenya and Zambia. Reprod Health Matters 2006;14:119-28.

32. Van Rossem R, Meekers D. The reach and impact of social marketing and reproductive health communication campaigns in Zambia. BMC Public Health 2007;7:352.

33. Banerjee SK, Andersen KL, Baird TL, et al. Evaluation of a multi-pronged intervention to improve access to safe abortion care in two districts in Jharkhand. BMC Health Serv Res 2014:14:227.

34. The Constitution of Zambia Bill 200- (draft). Available from the Ministry of Justice. https://www.zambia.co.zm/downloads/draft constitution.pdf (accessed 3 Sep 2015).

35. Shellenberg KM, Hessini L, Levandowski BA. Developing a scale to measure stigmatizing attitudes and beliefs about women who have abortions: results from Ghana and Zambia. Women Health 2014;54:599-616.

36. Bumpass LL. The measurement of public opinion on abortion: the effects of survey design. Fam Plann Perspect 1997;29:177-80. 
Correction: Women's knowledge and attitudes surrounding abortion in Zambia: a crosssectional survey across three provinces

Cresswell JA, Schroeder R, Dennis M, et al. Women's knowledge and attitudes surrounding abortion in Zambia: a crosssectional survey across three provinces. BMJ Open 2016;6:e010076. This paper has been resupplied with the CC BY license.

Open Access This is an Open Access article distributed in accordance with the terms of the Creative Commons Attribution (CC BY 4.0) license, which permits others to distribute, remix, adapt and build upon this work, for commercial use, provided the original work is properly cited. See: http://creativecommons.org/licenses/by/4.0/

BMJ Open 2016;6:e10076corr1. doi:10.113/bmjopen-2015-010076corr1

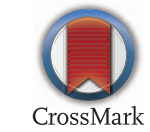

